\title{
Factors Influencing Serious Game's Integration in Educational System
}

\author{
Yassine Chajri \\ Sultan Moulay Slimane University \\ Beni Mellal \\ Morocco
}

\author{
Belaid Bouikhalene \\ Sultan Moulay Slimane University \\ Beni Mellal \\ Morocco
}

\begin{abstract}
The serious games' integration in educational system has become necessary due to its ability to attract learners' interest, stir their enthusiasm and ensure their commitment. This makes the learning process more enjoyable and more effective. But this integration process and the lack of comprehensive approaches that evaluate these games require identifying the factors that influence this integration's success. For this, we present in this paper the factors extracted from a survey study which targeted learners and teachers. This study aims to identify the various determinants influencing learning outcomes through games. Regarding the learners, we take into account only the characteristics which for them are indispensable in video games generally and that have been referred by more than $80 \%$ of the target group. The same percentage was also reserved for the factors that teachers admit are fundamental and crucial of the effectiveness of games' integration into the educational system. In addition, we focus a lot on how educational skills should be conveyed through the games' integration according to an effective pedagogical approach.
\end{abstract}

\section{General Terms}

Serious game's, Serious game's evaluation, Serious game's assessment

\section{Keywords}

Assessment- Educational system- Evaluation- game designLearning outcome- Serious games

\section{INTRODUCTION}

The rapid developments known by the technical and technological fields have greatly affected the daily life of societies as well as their behavioral and practical habits. For example, the use of modern technologies in educational learning process has had a positive impact in developing and improving its results. The incorporation of these technologies into the educational system led the role of the teacher related to orientation and organization, animation of discussions as well as developing and producing programs. It also contributed to the discovery of new possibilities and capabilities that did not exist before. Nowadays, the learners are becoming increasingly attached to smartphones and computers. More specifically, they are attached to digital games and play them with a lot of focus, enjoyment, energy and commitment. Therefore, this behavior should be directed towards the right path. For the same reason, games' proper use and connecting them to knowledge became necessary and urgent. The serious games can play this role and make this attachment a source of knowledge. The proponents of new pedagogies have long identified the potential of the game to develop the skills of exploration, systemic analysis and problem solving. The amazing development in the technical field has made serious games develop different and multiple competencies for their users. This made learning enjoyable and more effective. But the integration of these games into the educational system needs to assess their impacts. In the literature, there are many studies concerned with the topic of serious games assessment. But many of them do not evaluate it in its comprehensiveness. Therefore, we present in this paper the factors that influence the success of serious games integration into educational systems. The presentation of these factors was the result of a survey study that included teachers and learners. The questions that we were asked to learners related specifically to the factors motivating them and stimulating their enthusiasm in playing games. The teachers were asked questions related to all what is pedagogic regarding how to convey educational goals as well as the factors that would contribute to achieving the desired goals.

\section{SERIOUS GAME}

The Serious games term was first used in 1970 by Clark Abt to indicate the card games and board games designed for educational purposes [1]. Since that time, this term has become widely used. To clarify this term which consists of two words which can be seen contradictory "game" and "serious", we present in the table (Table 1) some definitions that can be interesting.

Table 1: Serious games' definitions.

\begin{tabular}{|c|c|}
\hline (Zyda, 2005) & $\begin{array}{l}\text { An intellectual challenge launched on } \\
\text { a computer according to specific } \\
\text { rules. It uses entertainment to serve } \\
\text { training, education, health, civil } \\
\text { security and as a communication } \\
\text { strategy in institutional or private } \\
\text { organizations [2]. }\end{array}$ \\
\hline $\begin{array}{l}\text { (Michael, et al., } \\
\text { 2005) }\end{array}$ & $\begin{array}{l}\text { A game that emphasizes education } \\
\text { rather than entertainment [3]. }\end{array}$ \\
\hline $\begin{array}{l}\text { (De Freitas and } \\
\text { Neumann, 2009) }\end{array}$ & $\begin{array}{l}\text { Serious games have the advantage to } \\
\text { offer environments allowing the } \\
\text { simulation of situations and contexts } \\
\text { in which learners can develop skills } \\
\text { [4]. }\end{array}$ \\
\hline $\begin{array}{l}\text { (Dupire, Labat, } \\
\text { and Natkin, 2011) }\end{array}$ & $\begin{array}{l}\text { The CERIMES has defined the } \\
\text { Serious games as «Applications } \\
\text { developed from advanced video game } \\
\text { technologies, using the same design } \\
\text { and savoir-faire approaches as } \\
\text { traditional video games, but which go } \\
\text { beyond the entertainment } \\
\text { dimension. »[5]. }\end{array}$ \\
\hline $\begin{array}{l}\text { (Wouters, et al., } \\
\text { 2007) and } \\
\text { (Pourabdollahian, } \\
\text { et al., 2012) }\end{array}$ & $\begin{array}{l}\text { Application of games which are } \\
\text { aimed at education and learning } \\
{[6][7] \text {. }}\end{array}$ \\
\hline
\end{tabular}




\begin{tabular}{|c|l|}
\hline $\begin{array}{c}\text { (Charsky, 2010) } \\
\text { and (Felicia, 2009) }\end{array}$ & $\begin{array}{l}\text { An activity whose the main purpose is } \\
\text { learning serious context through } \\
\text { playing [8][9]. }\end{array}$ \\
\hline $\begin{array}{c}\text { (Florence } \\
\text { Quinche) }\end{array}$ & $\begin{array}{l}\text { All video games that aim to transmit } \\
\text { content, to discover or learn } \\
\text { something [10]. }\end{array}$ \\
\hline
\end{tabular}

In recent years, serious games have grown considerably and have become a very important field of research. Michaud et al. classifies serious games into three categories (Serious games with message, Training games and Simulation games) [11]. For greater clarity, these serious games can be classified in:

- Educational games,

- Training games,

- Simulation games,

- Advertising games,

- Awareness games

- Informative games [12].

\section{SERIOUS GAME EXAMPLES}

The serious games market has experienced growing success in recent years [13]. This success is due to persistent needs of different fields. In particular, science, education, defense, civil security, health, marketing, etc. The table below (Table 2) provides an overview of some serious games and their categories.

Table 2: Serious games' examples.

\begin{tabular}{|c|c|}
\hline Serious game & Category \\
\hline Magnavox Odyssey & Education \\
\hline The Oregon Trail & Education \\
\hline Technocity & Education \\
\hline $\begin{array}{c}\text { Adi (pour Accompagnement } \\
\text { Didacticiel Intelligent) }\end{array}$ & Education \\
\hline Bradley Trainer & Simulation/training \\
\hline America's Army & Simulation/training \\
\hline Pulse! & Simulation/training \\
\hline First Responder Training & Simulation/training \\
\hline Virtual Battle Space : VBS & Simulation/training \\
\hline X-Plane 10 & Simulation/training \\
\hline Global Conflict : Palestine & Awareness \\
\hline Darfur is Dying & Awareness \\
\hline Chex Quest & Advertising \\
\hline
\end{tabular}

\section{FACTORS INFLUENCING THE SUCCESSFUL GAMES' INTEGRATION IN EDUCATIONAL SYSTEM}

There are many studies concerned with the topic of evaluating serious games. But many of them are limited in their evaluation to some axes and omit the other aspects. For example, there are lot of researches which were limited to evaluating the learning outcomes. In addition, there are studies that are concerned only with the characteristics that must be available in the serious game in order to attract the learner's interest. There are also few studies that are concerned with the games' design in terms of passing the games' purpose through pedagogical methods. Many studies overlook the impact of many characteristics on the success of the serious games such as: learners' characteristics and their preferences, teachers' qualities (programming, educational design, graphic design, etc.), educational spaces, etc.

For this reason, we present in this section the results of the study concerned with the factors influencing the successful games' integration in the educational system. Concerning the learners, we take into account only the characteristics which for them are indispensable in video games generally and that have been referred by more than $80 \%$ of the target group. While we have adopted the determinant factors of the successful of the serious games in achieving the desired outcomes, which were included by more than $80 \%$ of them.

\subsection{Game's purpose}

The serious games assessment system must begin by investigating the skills and knowledge that we want our learners to gain (game's purpose). Each game has its goals that the developers try to translate into the game's scenario. However, for a game to be integrated into educational system, it must have educational goals that are adequately designed with the session' time allotted for these games. Also, the rhythms of the game's educational activities must take into account the differences between learners and their preferences. This consistency between these elements allows learners to acquire knowledge and skills with a lot of flexibility and efficiency. Also, the game's purpose must be felt in the different stages of the game.

\subsection{Educational spaces}

The Organisation for Economic and Cooperation Development (OECD) defines "educational spaces" as " a physical space that supports multiple and diverse teaching and learning programmes and pedagogies, including current technologies; one that demonstrates optimal, cost-effective building performance and operation over time; one that respects and is in harmony with the environment; and one that encourages social participation, providing a healthy, comfortable, safe, secure and stimulating setting for its occupants" [14].

Regarding our approach of serious games assessment, we add the time dimension to educational space definition in order to become more inclusive. For us, this concept brings together all the spaces and time that allow the implementation of support for the formal educational act.

Concerning the serious games' integration into educational system, we need to have appropriate spaces equipped with all the necessary hardware, software and Internet. In order to succeed this integration, these equipments must be suitable with the game and also with the characteristics of the learners and their preferences. Indeed, providing these spaces with everything is necessary (structures, equipments and means) would increase the enthusiasm of the learners and their commitment. Without neglecting the time factor (morning period / evening period, session's duration) which should be considered as a basic determinant and must take into account the game's purpose and the differences between the learners and their preferences. All of this influence positively the learning outcomes.

\subsection{Learners profile}

Today, educational organizations are adopting learnercentered teaching approaches. In other words, the approaches that the teacher guides learners through the learning process, allowing them to learn and develop at their own pace and taking into account different learning styles. Indeed, the 
teaching methods must be adapted to the characteristics of the learners. Regarding serious games, their choice and design must take into account natural differences (biological and physiological) and acquired differences (culture, economic and social situation, the influence of the family and social environment, etc.) between learners. The choice of the game must also evoke the differences between the learners with regard to their own experiences with video games without losing sight of a basic determinant, learner's preferences.

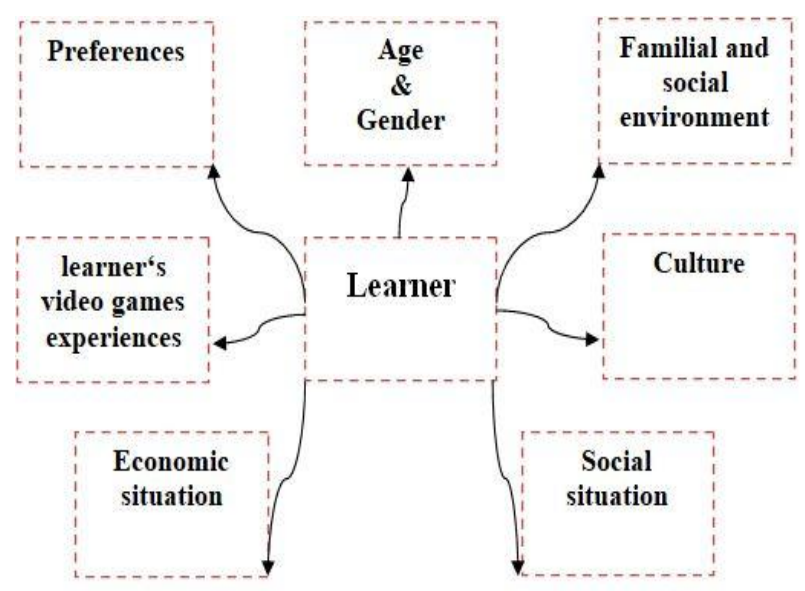

Fig 1: Learner's profile

\subsection{Game's design}

After studying and defining the characteristics of the target group and their preferences, as well as the game's purpose that should be translated into all the game phases. The game's design and ergonomics must comply with certain criteria which are essential for the validation of the design phase.

\section{- Playful aspects}

Students play video games with a lot of concentration, enjoyment, passion, energy and also with unlimited commitment. This behavior must be the same in their learning sessions. To do this, the serious game must include beautiful graphics, visual effects, sound effects and music in order to delight learners and stimulate their curiosity. At the first glance, all these combined things must be implicitly presented to the learners, an overview of game's purpose with a playful dimension. Serious games should play down learning process and put the light on the pleasure of learning. To do this, the skills and knowledge must be transferred / conveyed in consistent scenarios with a creative vision and imaginary sense. This creative vision must take into account the learners interests and their preferences. All this in order to stimulate the curiosity of learners and delight their enthusiasm, as well as to ensure their commitment and discipline.

Ease of use is a very important criterion in the development of serious games. It will contribute to arouse students' interest in playing it. On the contrary, if the game is complicated and the learners have difficulties to pass to the advanced levels of the game, they will often be frustrated. Thus, ignoring this criterion can have a huge impact on the user experience and therefore on the learning outcomes associated with serious games (learners need help on how the game works in order to overcome some obstacles related to the game use). In the game process, learners also need to be evaluated (feedback, progression, score, competition, etc.). All these parameters have only one objective, is the user's satisfaction.

\section{- Serious aspects}

Alvarez and Djaouti [15] defined the educational serious game by «a computer application which the initial intention is to combine, with consistency, both serious aspects such as teaching and learning, with playful springs » [16].

Indeed, for a serious game to be more effective, game's purpose must be conveyed with a playful dimension while keeping an unreal environment in order to give confidence to learners in their learning process [17]. Learners are rooted in certain representations which hinder them in their school career and limit their development. For example, most of them feel that errors and mistakes are not allowed in learning process. To remedy this problem, the educational serious game must place the learners in a zone of confidence where they can learn, by fun, by trial and error without risk and without suffering the consequences. In the literature, there is few works that are interested in the game's design in terms of passing targeted educational skills to learners. But, we were interested in the work presented by Serrano-Laguna, et al. [18]. The authors proposed a design where each learning goal is presented to the learners in three stages (Strategy, Practice and Mastery). In order to ensure the transfer of skills and knowledge in a relevant and efficient way, we present a game's design which each learning goal is presented to the learners in two stages:

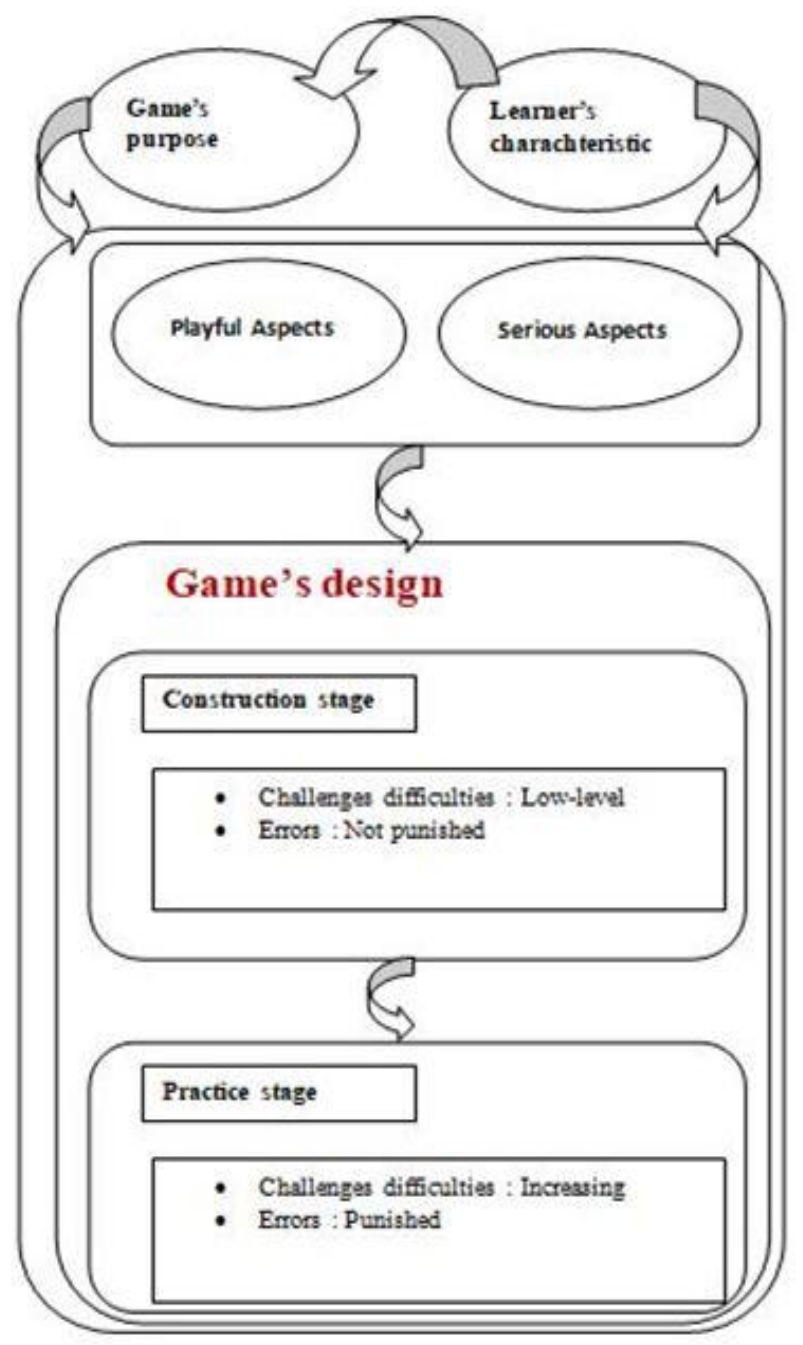

Fig 2: Serious game's design 
Construction stage: So that the learners do not feel in front of a lesson presented differently, we put them under the same conditions and in an environment that is no different, apparently, from video games that attract them by keeping their eyes tightly for hours and hours without boredom or fatigue (Proposal of help systems to unlock the learners and without presenting the educational objectives in order to allow them to learn and develop at their own pace).

In this stage, learners are invited to mobilize and integrate their knowledge and skills to develop strategies in order to meet the challenge they face. The degree of difficulty of each challenge at this stage must be in low-level and errors are not punished so as not frustrating learner's ambition and determination. This stage allows learners to learn from their errors and benefit greatly from their experiences to build their knowledge and skills.

Practice stage: The challenges at this stage are similar to those of the previous stage, but the degrees of difficulty increase in a pedagogical and gradual manner and errors are punished. Learners are required to adopt the strategies which have enabled them to solve the previous problems and to adapt them to this stage's developments. This step allows us to determine to what extent learners acquire the targeted skills and competencies.

\subsection{Teacher's qualities}

The success of the process of integrating serious games into educational system requires the availability of highly qualified teachers with knowledge and skills in programming, educational design, graphic design, pedagogical scenarisation, etc. These qualities allow teachers to choose the serious game that suits the targeted skills and abilities and also to know if the game's purposes are transmitted according to an pedagogical consistent vision with the curriculum. In addition, they determine the technical requirements based on the characteristics of each game. In addition, at the end of the learning process, teachers evaluate the serious game sessions (effectiveness of the chosen serious game) and the learners' acquisition.

\subsection{Learning outcomes}

We consider the learning outcomes as the most important characteristic of the effectiveness of the serious game in achieving the targeted competencies and skills. Learning outcome refers to the competencies and knowledge gained by the learners after their interactions with the serious game. There are several studies concerned with learning outcome's analysis. Some of them used qualitative and/or quantitative methods in their analysis [19],[20], [21]. Other studies analyze learning outcomes through answers obtained from questions included in the game [22]. Wouters, et al. [23] divided learning outcomes into four categories (cognitive, motor skills, affective and communicative). Serrano-Laguna, et al. [18] proposes a non-disruptive assessment alternative to questionnaires.

\section{CONCLUSION}

There are many serious games that are used for educational purposes, but some are interested in the playful aspects that stimulate learners, while others focus a lot on the educational aspect in them, which makes learners not enthusiastic about them. This imbalance affects negatively the learning outcomes. For this reason, we did a survey study targeting learners and teachers. Based on the results of this study, we identified the factors that influence the success of serious games integration into educational systems. We presented, in this paper, our perceptions for each of these factors. The game's purpose must be well defined taking into account the characteristics of the targeted learners and all other factors. Concerning educational spaces (physical spaces, time), we have defined its characteristics and how it should be. In addition, we have identified the characteristics of learners that must be taken into consideration while designing the serious game. But the main focus was on serious game's design, we have raised the playful aspects that must be provided in the game in order to stimulate the enthusiasm of learners and ensure their commitment. Also, we provided a design for how educational skills should be passed. In this design, each of educational goals must be presented to the learners in two stages (Construction stage and Practice stage) to enable them to build their learning. In this paper, we did not lose sight of the roles that teachers play and the qualities that they must have in order to succeed the process of serious games integration. Finally, we presented some methods that allow the learning outcome's analysis.

\section{REFERENCES}

[1] Abt, C. 1970. Serious Games, University Press of America.

[2] Zyda, M. 2005. From Visual Simulation to Virtual Reality to Games, IEEE Computer, vol. $38, n^{\circ}$ 9, p. 25 32.

[3] Michael, D. R. and Chen S. L. 2005. Serious Games : Games That Educate, Train, and Inform, Muska \& Lipman/Premier-Trade.

[4] De FREITAS, S. and NEUMANN, T. 2009. The use of 'exploratory learning' for supporting immersive learning in virtual environments. Computers and Education Journal, 52(2), 343-352.

[5] Dupire, J., Labat, J.M. and Natkin, S. 2011. Du jeu sérieux au jeu utile. Revue d'intelligenceartificielle, 25(2), 143- 146.

[6] Wouters, P., Tabbers, H. K. and Paas, F. 2007. Interactivity in video_based models, Educational Psychology Review, p. 327342.

[7] Pourabdollahian, B., Taisch. M. and Kerga. E. 2012. Serious Games in Manufacturing Education: Evaluation of Learner's Engagement. Procedia Computer Science $15,256-265$.

[8] Charsky, D. 2010. From edutainment to serious game : A change in the use of game characterisitcs, Games and culture. p. 177-198.

[9] Felicia, P. 2009. Learning in immersive worlds: A review of game based learning, JiSC.Available at:www.jisc.ac.uk/whatwedo/programmes/elearninginno vation/outcomes.aspx, 2009.

[10] Quinche, F. 2013. Game Based Learning, Apprendre avec les jeux video, Institut suisse des médias pour la formation et la culture. Available at : http://guides.educa.ch/sites/default/files/educa.guides_ga mebasedlearning_fr_0.pdf.

[11] Michaud, L. and Alvarez, J. 2008. Serious games advergaming, edugaming, training..., Montpellier, Idate.

[12] Schmoll, P. 2011. Jeux sérieux : exploration d'un oxymora, Revue des Sciences sociales, Presses Universitaires de Strasbourg, Jeux et enjeux pp.158-167.

[13] MacIntyre, J. Maglogiannis, I. Iliadis, L. and Pimenidis, 
E. 2019. Artificial Intelligence Applications and Innovations, 15th IFIP WG 12.5 International conference , AIAI 2019. Hersonissos, Crete, Greece, Proceedings.

[14] Kuuskorpi, K. and Gonzàlez, N. 2011. The future of the physical learning environment: school facilities that support the user, CELE Exchange- ISSN 2072-7925.

[15] Alvarez, J. and DJAOUTI, D. 2010. Introduction in Serious Game (2nd ed). Question théorique.

[16] Ezziyyani, M. 2019. Advanced Intelligent Systems for Sustainable Development. Advances in Intelligent Systems and Computing. ISBN 978-3-030-11883-9.

[17] Djaouti, D. 2011. Serious Game Design : considérations théoriques et techniques sur la création de jeux vidéo à vocation utilitaire. Université de Toulouse.

[18] Serrano-Laguna, A. Manero, B. Freire, M. and Fernández-Manjón, B. 2017. A methodology to assess the effectiveness of serious games and infer player learning outcomes, Multimedia Tools and Applications.

[19] Baker, A. Zhang, J. and Caldwell, R. E. 2012. Reinforcing Array and Loop Concepts Through a Game-
Like Module, The 17th International Conference on Computer Games, pp. 175-179.

[20] Malliarakis, C. Satratzemi, M. and Xinogalos, S. 2014. CMX: Implementing an MMORPG for Learning Programming, Proceeding of the European Conference on Games-based Learning, pp. 346-355.

[21] Wangenheim, G. C. Savi, R. and Borgatto, F. A. 2012. DELIVER! - An educational game for teaching Earned Value Management in computing courses, Information and Software Technology, Vol. 54, pp. 286-298.

[22] Dudzinski, M. Greenhill, D. Kayyali, R. et al. 2013. The Design and Evaluation of a Multiplayer Serious Game for Pharmacy Students, In: Proc. 7th Eur. Conf. Games Based Learn. Vols 1 2. pp 140-148.

[23] Wouters, P. Van der Spek, E. and Van Oostendorp, H. 2009. Current practices in serious game research: A review from a learning outcomes perspective, Gamesbased learning advancements for multisensory human computer interfaces: Techniques and effective practices, pp. 232-255. 